\title{
Misplaced intra uterine devices: a rare case of vaginal entrapment
}

\author{
Anshul Grover*, Sumita Mehta, Ankita Mann
}

Department of Obstetrics and Gynaecology, Babu Jagjiwan Ram Memorial Hospital, Delhi, India

Received: 01 September 2019

Accepted: 01 October 2019

\section{*Correspondence:}

Dr. Anshul Grover,

E-mail: anshul_abc@yahoo.com

Copyright: (c) the author(s), publisher and licensee Medip Academy. This is an open-access article distributed under the terms of the Creative Commons Attribution Non-Commercial License, which permits unrestricted non-commercial use, distribution, and reproduction in any medium, provided the original work is properly cited.

\section{ABSTRACT}

Intra uterine devices (IUD) are the second most common accepted methods of contraception worldwide after sterilization. It is a long acting reversible contraceptive (LARC) which is now being promoted as a simpler, safer and effective method of contraception for those women who do not want a permanent method of contraception. Missing thread is the most common complaint seen within 6 weeks of insertion and may be the only presentation of misplaced IUD. Most women who spontaneously expel the IUD are unaware of the situation. We are presenting a case of misplaced IUD which was partially expelled and got embedded in the vagina which is a rare site of misplaced IUD.

Keywords: Postpartum, Contraception, Temporary, Intra uterine devices, Misplaced, Long acting reversible contraceptive

\section{INTRODUCTION}

Intrauterine device is a long acting reversible contraceptive (LARC) which can be used in various phases of a women's reproductive life, including post abortion, post-partum and interval period. Missing thread is the most common complaint seen within 6 weeks of insertion and may be the only presentation of misplaced IUD.

The common sites of misplaced IUD are the lower uterine segment, the cervix and after perforation of the uterine wall- the abdominal cavity. No case of vaginal entrapment of an IUD has been discussed in the literature so far. We are presenting a case of misplaced IUD which was partially expelled and got embedded in the vagina which is a rare site of misplaced IUD.

\section{CASE REPORT}

A 28-year-old G3P2L1 presented at 37 weeks 6 days period of gestation to the labor delivery ward of our hospital in active labor. During her vaginal examination an unusual finding was noticed - arms of multiload 375, an intrauterine copper containing device (IUD) were found embedded in the posterior vagina on the left side (Figure 1). On reviewing her history, it was established that the patient had a previous vaginal delivery 16 months back during which she had accepted post placental insertion of IUD (Multiload 375) as a family planning measure.

The patient did not follow up for checkup at 6 weeks postpartum as recommended and neither felt for the threads of the IUD at any time after insertion. She conceived again during lactation amenorrhea at 7 months postpartum. Her first obstetric ultrasound performed at 16 weeks did not mention any intrauterine or extra uterine device. According to the patient she assumed that the IUD had expelled spontaneously and therefore she had conceived. She underwent routine regular antenatal examination from 18 weeks of gestation but no per vaginal examination was performed at any visit. She gave no history of any vaginal discomfort, dysparunia, bleeding or abnormal vaginal discharge during 
pregnancy. Her antenatal period was uneventful and she went into spontaneous labor at 37 completed weeks.

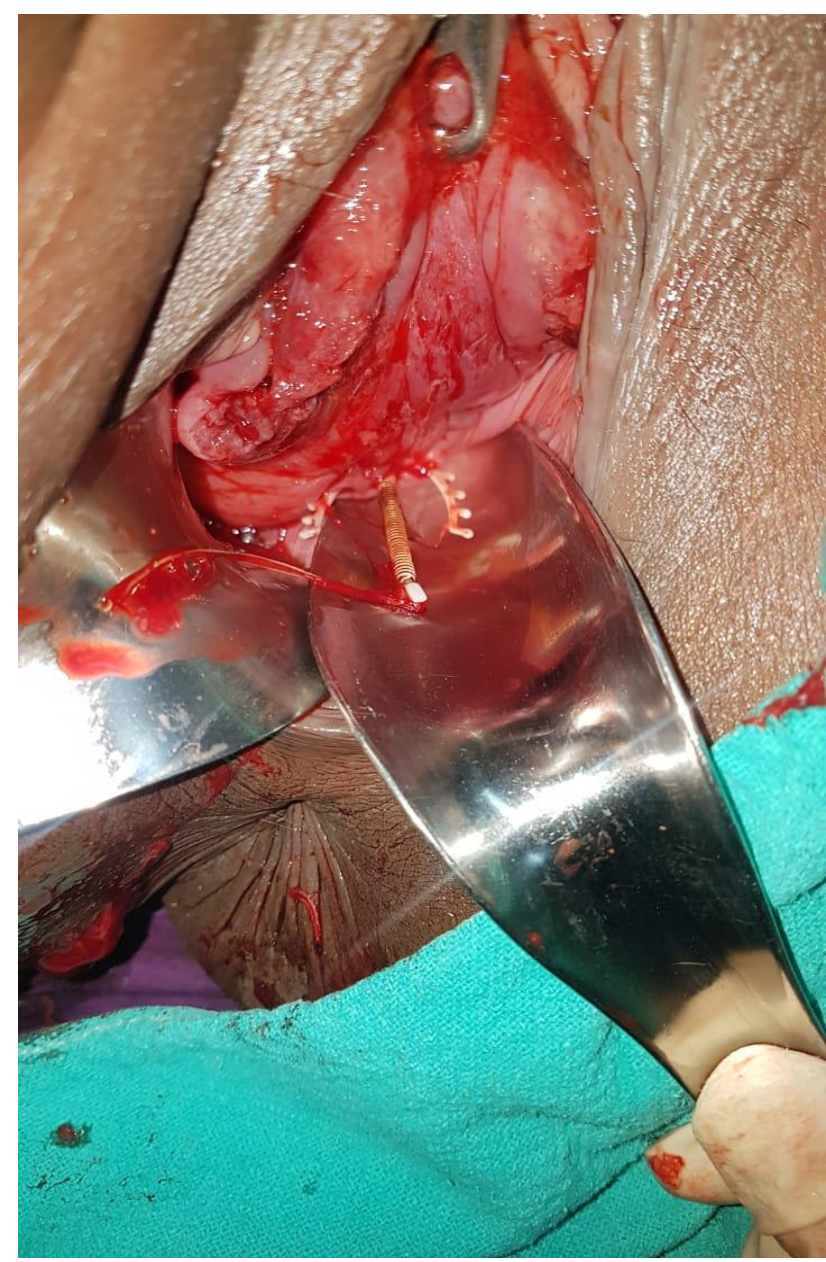

Figure 1: IUCD Embedded in posterior vagina.

Her labor progressed normally and she delivered a healthy baby girl of $2.7 \mathrm{~kg}$. Post-delivery an attempt was made to pull out the IUD arms from the vagina using an artery forceps but was not successful. The patient was then reevaluated under general anesthesia. Per operatively it was found that the arms of the IUD had pierced the vaginal mucosa like an earring and their junction with the stem of the IUD had become adherent to the posterior vaginal wall. A $1 \mathrm{~cm}$ incision was given over the vaginal mucosa overlying the adherent part of the IUD and it was released. The incision was then closed with polygalactin 2.0 suture and hemostasis was achieved. The postoperative period was covered with routine antibiotics and the patient was discharged after 48 hours.

\section{DISCUSSION}

Intra uterine contraceptive devices (IUD) are very effective, long term, reversible methods of contraception which form the backbone of the family planning services in developing countries like India. IUD's have the advantage of multiple options of insertion such as immediate postpartum, in the puerperal period, post- abortal and post-menstrually. They have a failure rate of $<$ I per 1000, thus making them as effective as permanent methods of sterilization. ${ }^{1}$ Insertion and removal of IUD is an outpatient procedure and does not demand any special preparation. The return of fertility after removal of IUD is immediate. All these factors make it an easily acceptable female contraceptive. With the revival of IUD as an efficient postpartum contraceptive by the Government of India in the family planning program, the number of postpartum insertions of IUD has drastically increased. ${ }^{2}$

Misplaced IUD is defined as non-localization of the tail of the IUD at the cervical os. ${ }^{3}$ One of the most common causes for this is if the threads break or curl up in the endometrial cavity. Other causes include enlargement of uterus as a result of pregnancy, IUD embedded in the endometrium, spontaneous expulsion of the IUD and rarely if uterine perforation has occurred. The incidence of missing threads varies between $5 \%$ and $25 \%$ in various studies. ${ }^{4-7}$ Postpartum insertions are commonly associated with curling up of the thread in the enlarged uterine cavity. These patients should be evaluated with pelvic ultrasound and if need be on hysteroscopy. In about $95 \%$ of these cases on further evaluation the IUD may be located within the endometrial cavity or may be displaced to the endocervical canal. ${ }^{4}$ Expulsion of IUD is usually higher in the postpartum period as compared to post abortion or interval IUD insertion with incidence as high as $10-27 \% .^{8}$ Jatlaoui et al, reviewed various metaanalysis to conclude that pooled rates of expulsion varied according to timing of insertion. It ranged from $1.9 \%$ with interval placements, $10 \%$ with immediate placements and $29.7 \%$ with early postpartum placements. ${ }^{9}$ The UN-POPIN (United Nations Population Information Network) report also concluded a $9 \%$ expulsion rate with immediate postpartum IUD insertion as compared to an alarmingly high incidence of $37 \%$ with delayed postpartum insertions. ${ }^{10}$ Some authors like Gupta et al and Letti Muller et al, have also reported higher rates of expulsion post vaginal as compared to post caesarean delivery. ${ }^{11,12}$ Studies have also shown that skills, experience and grade of the service provider is an important consideration resulting in complications such as expulsions and perforation. ${ }^{13}$

Kittur et al and Hooda $\mathrm{R}$ et al, highlighted the importance of follow up after insertion to address to any complications and for follow up counseling. ${ }^{14,15}$ Our patient was a defaulter, who did not have any follow up after IUD insertion, which led to an unplanned pregnancy. This reinstates that proper follow up is the backbone of any contraceptive program. The acceptor must be counseled for their first follow up visit at 6 weeks or earlier in case of any problem. All health providers must examine the women by per speculum and per vaginal examinations even if they do not have a complaint to pick up any misplaced threads or even displaced IUD's which in most cases are asymptomatic but may be a cause of failure of the device. Kittur et al in their study even enquired from the women regarding 
complications telephonically and called them back for evaluation if required.

Of the reported cases of misplaced IUD lying outside the uterine cavity, the locations usually identified were within the pelvis or rarely the upper abdomen, but no case of it being localized in the vaginal fornix has been reported till now. In an IUD acceptor, the occurrence of pregnancy demands evaluation to locate the intrauterine device by examination and pelvic ultrasonography. As in our case, the patient presented at 18 weeks of gestation for antenatal check-up. She gave history of previous postpartum IUD insertion, but her obstetric ultrasound did not suggest any placental embedded IUD. Therefore, it was assumed to have been spontaneously expelled. A basic per vaginal examination at her first antenatal visit may have been able to locate the IUD. The strange location of the IUD arms suggests that probably the device was under the process of spontaneous expulsion.

\section{CONCLUSION}

This case highlights the importance of IUD tracking cards, and regular follow up. The success of any program resides in its follow up to assess acceptability, identify and treat complications and generate confidence in the acceptor's mind. A complete clinical evaluation including a speculum evaluation to assess the IUD must be performed in all patients even if no symptoms are present at every follow up visit. It also reinstates the importance of a speculum examination for all women who present to the gynecological outpatient department and even during antenatal check-up as an opportunity to detect any abnormalities of the cervix and vagina.

Funding: No funding sources

Conflict of interest: None declared

Ethical approval: Not required

\section{REFERENCES}

1. Anna G. Dewhurt's Textbook of Obstetrics and Gynaecology. Edmonds DK, editor. Contraception. 7th edition. India: Willey; 2007:309-310.

2. Basu S, Green M, Stanback J. Program assessment of the introduction of multiload-375 IUD in the family welfare program of the government of India WHO 2015. J Pregnancy Reprod. 2018;2(5):7-7.

3. Howkins and Bourne; Birth Control and Medical Termination of Pregnancy. Shaw's Textbook of Gynecology; 15th ed. Editors V.G. Padubidri, SN Daftry Elsevier; 2011:229-230.

4. Marchi NM, Castro S, Hidalgo MM, Hidalgo C, Monteiro-Dantas C, Villarroeal $\mathrm{M}$, et al. Management of missing strings in users of intrauterine contraceptives. Contracep. 2012;86(4):354-8.

5. Verma A, Sinha AR. Study of postpartum IUCD insertion in Tertiary Health care center in Bihar: Indian J Perinatol Reproduct Biol. 2014;4:8-10.

6. Shukla M, Qureshi S. Post placental intrauterine device insertion- a five-year experience at a tertiary care center in North India. Int $\mathrm{J}$ Med Res. 2012;136:432-5.

7. Garg N, Grover S, Kaur B. Postpartum IUCD: its acceptance and complications. Int $\mathrm{J}$ Reprod Contracept Obstet Gynecol. 2017;6:2973-7.

8. ACOG LARC Program: Immediate Postpartum IUD Expulsion Fact Sheet. https://www.acog.org.

9. Jatlaoui TC, Whiteman MK, Jeng G, Tepper NK, Berry-Bibee E, Jamieson DJ, et al. Intrauterine device expulsion after postpartum placement: a systematic review and meta-analysis. Obstet Gynecol. 2018;132(4):895-905.

10. United Nations Population Information Network (POPIN) UN Population division, Department of Economic and Social affairs with support from UN Population fund. Network Intrauerine devices. Family Health International. Winter; 1996:16-2.

11. Gupta A, Verma A, Chauhan J. Evaluation of PPIUCD versus interval IUCD (380A) insertion in a teaching hospital of Western UP. Int J Reprod Contracept Obstet Gynecol. 2013;2(2):204-8.

12. Muller Müller AL, Ramos JG, Martins-Costa SH, Dias RS, Valério EG, Hammes LS, et al. Transvaginal ultrasonographic assessment of the expulsion rate of intrauterine devices inserted in the immediate postpartum period: a pilot study. Contracept. 2005;72(3):192-5.

13. Sharma R, Suneja A. Incarceration and transmigrated intrauterine contraceptive devices managed at a tertiary care teaching hospital of east Delhi: a retrospective analysis. J Obstet Gynaecol India. 2019;69(3):272-8.

14. Kittur S, Kabadi YM. Enhancing contraceptive usage by post -placental intrauterine contraceptive devices (PPIUCD) insertion with evaluation of safety, efficacy, and expulsion. Int J Repro Contraception. 2004;69:279-82.

15. Hooda R, Mann S, Nanda S, Gupta A, More H, Bhutani J. Immediate postpartum intrauterine contraceptive device insertions in caesarean and vaginal deliveries: a comparative study of follow-up outcomes. Int J Repro Med. Aug 17, 2016.

Cite this article as: Grover A, Mehta S, Mann A. Misplaced intra uterine devices: a rare case of vaginal entrapment. Int J Reprod Contracept Obstet Gynecol 2019;8:4599-601. 